\title{
Notificação Compulsória e Fisioterapia: um olhar sobre o ensino
}

\author{
Geraedson Aristides da Silva \\ Fisioterapeuta, mestrando em Ensino em Saúde e Tecnologia pela \\ Universidade Estadual de Ciências da Saúde de Alagoas - UNCISAL \\ 凶 geraedson@hotmail.com \\ Geraldo Magella Teixeira \\ Fisioterapeuta, Doutor em Ciências e Vice-coordenador do Mestrado em Ensino em Saúde \\ e Tecnologia pela Universidade Estadual de Ciências da Saúde de Alagoas - UNCISAL \\ Almira Alves dos Santos \\ Odontóloga, Doutora em Odontopediatria e Coordenadora do Mestrado em Ensino em Saúde \\ e Tecnologia da Universidade Estadual de Ciências da Saúde de Alagoas - UNCISAL
}

Recebido em 23 de novembro de 2018

Aceito em 25 de abril de 2019

\section{Resumo:}

A Notificação Compulsória (NC) é a comunicação obrigatória às autoridades, realizada por profissionais ou responsáveis por estabelecimentos de saúde, públicos ou privados, sobre a ocorrência de suspeita ou confirmação de doença, agravo ou evento de saúde pública. Diante do exposto, este artigo caracterizado como uma pesquisa quali-quantitativa de abordagem descritiva-analítica associado a uma revisão de literatura, objetiva identificar informações pertinentes aos cursos alagoanos de Fisioterapia através do e-MEC e avaliar em seus respectivos Projetos Políticos dos Cursos a existência de disciplinas ou conteúdos em ementas sobre NC. Entre os resultados, constatou-se que doze instituições de ensino ofertam o curso em Alagoas-Brasil, distribuídos na modalidade presencial e a distância, assim, perfazendo um número alto de formandos que necessitam de conhecimento sobre a temática. O presente trabalho concluiu que os cursos alagoanos de Fisioterapia, demandam adequações nas estruturas curriculares, para que seus egressos sejam capazes de contribuir efetivamente com as estratégias ministeriais sobre NC.

Palavras-chave: Saúde, Notificação Compulsória, Ensino, Fisioterapia.

\section{Mandatory Reporting and Physical Therapy: a look at teaching}

\begin{abstract}
:
Mandatory Reporting (MR) is the obligatory communication to the authorities, made by professionals or responsible for public or private health facilities, regarding the occurrence of suspicion or confirmation of illness, public health event or damage. In light of the foregoing, this paper characterized as a qualitative-quantitative research of a descriptive-analytical approach associated to a literature review aims to identify pertinent information to the physiotherapy courses in Alagoas through e-MEC and to assess in their respective Political Projects of the Courses the existence of subjects or contents in menus on MR. Among the results, we noted that twelve educational institutions offer the course in Alagoas-Brazil, distributed in face-to-face and distance education, thus reaching a large number of trainees who need knowledge about this topic. This study has concluded that the Alagoas Physiotherapy courses require adjustments in the curricular
\end{abstract}


structures, so that their newly-trained are able to effectively contribute to the ministerial strategies on MR.

Keywords: Health, Mandatory Reporting, Physical Therapy Specialty, Teaching.

\title{
Notificación Obligatoria e Fisioterapia: una mirada sobre la enseñanza
}

\begin{abstract}
Resumen:
La Notificación Obligatoria (NO) es la comunicación imprescindible para las autoridades, efectuada por profesionales o responsables por establecimientos de salud públicos o privados, sobre la ocurrencia de sospecha o confirmación de enfermedad, daño o evento de salud pública. Ante lo expuesto anteriormente, este artículo caracterizado como una investigación cualitativacuantitativa de un enfoque descriptivo-analítico asociado con una revisión de la literatura se centra en identificar la información pertinente a los cursos de fisioterapia de Alagoas mediante el e-MEC y evaluar en sus respectivos Proyectos Políticos de Carreras la existencia de asignaturas o contenidos en los menús de NO. Entre los resultados, se notó que doce instituciones de enseñanza ofrecen la carrera en Alagoas-Brasil, distribuidos en la modalidad presencial y a distancia, alcanzando así un número alto de alumnos concluyentes que necesitan conocimiento sobre el asunto. El presente trabajo concluyó que los cursos de Fisioterapia de Alagoas requieren adecuaciones en las estructuras curriculares, para que sus egresados sean capaces de contribuir efectivamente con las estrategias ministeriales sobre NO.
\end{abstract}

Palabras clave: Enseñanza, Notificación Obligatoria, Fisioterapia, Salud.

\section{INTRODUÇÃO}

A Portaria ministerial 204, além de definir a Lista Nacional de Notificação Compulsória (NC), também apresenta doenças, agravos e eventos de saúde nos serviços de saúde públicos ou privados em todo território nacional, levando em consideração a promoção, proteção e recuperação da saúde. O documento, ainda considera a necessidade de padronizar os procedimentos normativos relacionados a NC no âmbito do Sistema Único de Saúde (SUS) e torna-a obrigatória para profissionais de saúde (BRASIL, 2016).

Entretanto, a configuração do ensino sobre NC aos estudantes da saúde ainda diverge das estratégias do Ministério da Saúde, isso ocorre também pelas divergências dos Projetos Políticos dos Cursos (PPCs) e pelo fato da maioria dos profissionais de saúde atribuir a responsabilidade da NC exclusivamente ao médico. Nos cursos da saúde, a maioria dos PPCs não dispõe da especificidade do estudo das doenças infectocontagiosas, desencadeando uma precariedade no conhecimento dos acadêmicos, que no futuro, terão dificuldades para reconhecer e tomar medidas cabíveis e em tempo hábil junto ás autoridades de saúde (VASCONCELOS, 1998; NUNES, 2005; ANDRADE, 2012). 
Ações de vigilância ministeriais são inviabilizadas quando a formação do profissional de saúde não privilegia o ensino relacionado a NC, pois, vários agravos e enfermidades são considerados endêmicos nas regiões brasileiras, sendo assim, necessárias estratégias de promoção, proteção e controle da situação; e, em função disso, sugere-se melhor treinamento de profissionais e acadêmicos da saúde no âmbito das instituições de ensino superior (SILVA, 2015).

No caso específico da formação do fisioterapeuta, autores como Campos et. al. (2001) e Dias, Cyrino e Lastória (2007) discorrem sobre a necessidade da implementação de novas práticas pedagógicas nos cursos de graduação, para que o profissional possa, em seu cotidiano, ser capaz de lidar com as condições diferentes de saúde da população, inclusive referentes a NC.

Nesse direcionamento, os Projetos Políticos Pedagógicos dos cursos de fisioterapia devem atender não só o conhecimento técnico-científico, mas, o encorajamento ético-político com perspectivas relacionadas à cidadania e emancipação dos sujeitos e coletividades, criando possibilidades para o futuro fisioterapeuta intervir na realidade e desempenhar seu de trabalho de forma crítico-reflexiva, valorizando a interdisciplinaridade e os aspectos humanísticos, voltados para as demandas de saúde da população (BISCARDE; PEREIRA-SANTOS; SILVA, 2014).

Dito isto, acredita-se que há uma necessidade urgente dos cursos de Fisioterapia alagoanos desenvolver em seus PPCs, atividades que valorizem o aprendizado, entrelaçando as atividades já existentes com atividades que favoreçam a sociedade em geral com relação a NC. Uma alternativa para maximizar as estratégias ministeriais sobre a NC, além da divulgação por mídia impressa e online, já existente, seria a implementação dos PPCs, com projetos de extensão, que objetivam promover cidadania e produzir conhecimentos, além de incentivar reflexões acerca de possíveis transformações na condução da promoção de saúde e no controle de agravos à população (MOURA et al., 2012).

Outra alternativa seria a implantação ou adequação de disciplinas e cursos extracurriculares através da educação a distância, que tem assumido, a cada dia, maior participação na formação educacional, em especial no ensino superior, através de ferramentas que usualmente não são utilizadas nas modalidades tradicionais de ensino, porém, viabilizam para o discente uma formação continuada (GOMES, 2013). 


\section{MATERIAIS E MÉTODOS}

Este trabalho refere-se a uma pesquisa quali-quantitativa de abordagem descritiva-analítica, desenvolvido a partir dedados dos cursos de Fisioterapia no Estado de Alagoas e seus respectivos Projetos Políticos Pedagógicos. Os dados referentes ao funcionamento dos cursos foram retirados do Portal e-MEC - site vinculado ao Ministério da Educação (MEC) do Brasil, associado ao estudo, também, realizou-se uma revisão integrativa sobre o preparo de estudantes de fisioterapia acerca da NC.

De forma estratégica, foram buscados dados dos cursos de fisioterapia credenciados pelo MEC no estado de Alagoas e através do endereço eletrônico e-MEC, foram localizadas todas instituições de ensino superior que ofertam o curso.

No e-MEC, foram buscadas informações como: modalidade de ensino, data de início de funcionamento, carga horária ( $\mathrm{CH}$ ) mínima, periodicidade (integralização) e número anual de vagas. Após este processo, buscou-se nos endereços eletrônicos das instituições de ensino, os Projetos Políticos Pedagógicos e suas respectivas matrizes curriculares e por fim os conteúdos relacionados aos Sistema de Notificação do Brasil, este processo ocorreu concomitantemente com a revisão de literatura.

Foi elaborada uma estratégia de busca nas bases de dados: Portal Periódico CAPES (Coordenação de Aperfeiçoamento de Pessoal de Nível Superior), LILACS (Literatura LatinoAmericana e do Caribe em Ciências da Saúde) e SciELO (Scientific Electronic Library Online) a partir do cruzamento dos seguintes Descritores em Ciências da Saúde (DeCS): Ensino, Fisioterapia, Notificação Compulsória e Saúde. Estas palavras, foram combinadas por meio do conector booleano "and" igual o modelo proposto por Spana et al., (2008). Não houve restrição quanto ao ano de publicação.

Seguida a fase de seleção os artigos foram submetidos aos critérios inclusão, a saber: artigos originais sobre NC, relacionados ao Ensino e a Fisioterapia. Os artigos encontrados também foram submetidos aos seguintes critérios de exclusão: estudos que desvirtuam da questão norteadora e artigos duplicados.

A partir da aplicação da estratégia de busca contendo os descritores definidos, a seleção dos artigos encontrados foi realizada em duas etapas: identificação e leitura dos títulos e resumos nas diferentes bases eletrônicas de dados, foram excluídos aqueles que, claramente, não se enquadravam em qualquer um dos critérios de inclusão deste estudo; todos os estudos que não 
foram excluídos na primeira etapa foram lidos na íntegra para seleção dos que seriam incluídos na revisão.

Posteriormente os resumos foram lidos, excluindo-se aqueles, que não se relacionavam com a temática. Finalmente, realizou-se a leitura integral dos demais artigos, ocorrendo nova exclusão daqueles que não se adequavam a proposta deste trabalho, por fim utilizou-se dezessete estudos, na composição da revisão.

\section{RESULTADOS}

As Instituições de Ensino Superior (IES) foram pesquisadas e agrupadas de acordo com informações encontradas no portal do e-MEC, e representadas por letras alfabéticas, de "A" a "M", de acordo com o Quadro 1.

Todos os cursos atendem a carga horária mínima de quatro mil horas, exigidas pelas Diretrizes Curriculares do Curso de Fisioterapia (BRASIL, 2002). Os cursos foram ordenados de acordo com o início do seu funcionamento, sendo o mais antigo e o único a ser ofertado por uma IES pública, datado no ano de 1997. Os demais cursos são ofertados por IES privadas, sendo os três mais recentes datados em 2017, como mostra o quadro 1 (pagina seguinte).

No e-MEC, foram encontradas doze IES que ofertam o curso de Fisioterapia no estado de Alagoas, sendo dez instituições localizadas na capital do estado (Maceió) e duas localizadas na cidade de Arapiraca, interior do estado, totalizando 1.296 vagas, não considerando o curso "M" que não apresenta o número de vagas. 
Quadro 1 - Perfil das faculdades de fisioterapia alagoanas. * Cursos ofertados na modalidade a distância.

\begin{tabular}{|c|c|c|c|}
\hline $\begin{array}{c}\text { INSTITUIÇÃO DE } \\
\text { ENSINO }\end{array}$ & $\begin{array}{c}\text { INÍCIO DO } \\
\text { FUNCIONAMENTO }\end{array}$ & $\begin{array}{c}\text { CARGA } \\
\text { HORÁRIA } \\
\text { MÍNIMA }\end{array}$ & $\begin{array}{c}\text { NÚMERO } \\
\text { ANUAL DE } \\
\text { VAGAS }\end{array}$ \\
\hline A & $27 / 05 / 1997$ & 4.720 & 40 \\
\hline B & $19 / 07 / 2000$ & 4.000 & 240 \\
\hline C & $02 / 05 / 2002$ & 4.572 & 200 \\
\hline D & $10 / 02 / 2007$ & 4.000 & 100 \\
\hline E & $02 / 02 / 2009$ & 4.520 & 96 \\
\hline F & $02 / 02 / 2009$ & 4.035 & 100 \\
\hline G & $01 / 03 / 2011$ & 4.000 & 100 \\
\hline H & $01 / 12 / 2015$ & 4.010 & 100 \\
\hline I & $07 / 10 / 2016$ & 4.020 & 100 \\
\hline J & $13 / 02 / 2017$ & 4.000 & 120 \\
\hline L & $20 / 11 / 2017^{*}$ & 4.000 & 100 vagas \\
\hline M & $20 / 11 / 2017^{*}$ & 4.000 & Não Consta \\
\hline
\end{tabular}

Autoria própria, 2019.

Constatou-se que, 92\% das IES cumprem o limite mínimo para integralização do curso, que é de cinco anos, de acordo com a Resolução nº 2 de 18 de junho de 2007 (BRASIL, 2007), com exceção da instituição "D" cujo início do funcionamento é datado em fevereiro de 2007, esta instituição oferta o curso no período de quatro anos. Quando avaliadas as modalidades de ensino encontrou-se os seguintes resultados: 
Gráfico 1 - Oferta dos Cursos de Fisioterapia em Alagoas.

\section{Oferta de Cursos em Alagoas-Brasil}

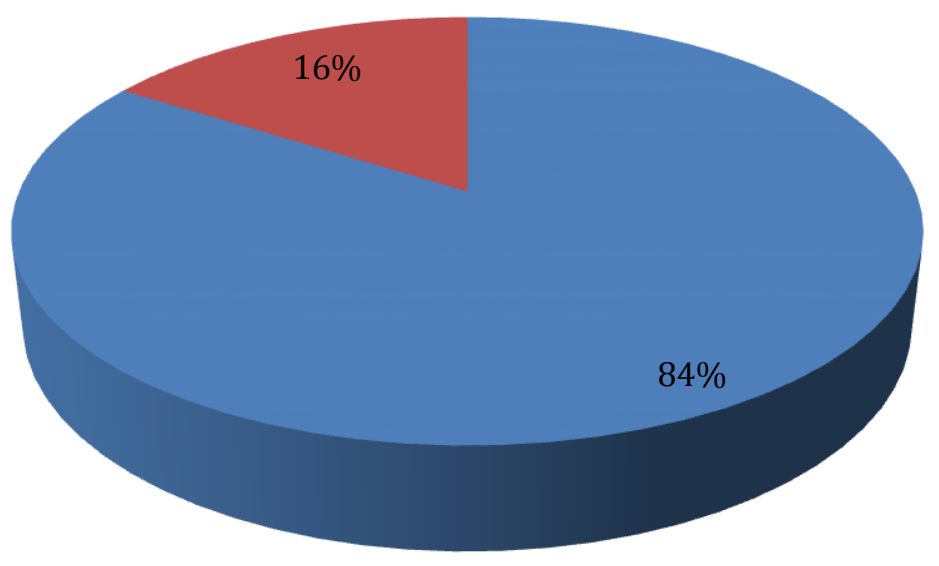

Presencial

A Distância

Autoria própria, 2019.

Dentre os cursos ofertados, $84 \%$ são presenciais e $18 \%$ a distância. Dos presenciais, nove encontram-se na capital alagona e um no interior do estado, todos em pleno funcionamento. Os dois cursos ofertados na modalidade a distância não se encontram em atividades.

Gráfico 2 - PPC de Fisioterapia de Alagoas-Brasil.

\section{PPC de Fisioterapia de Alagoas-Brasil}

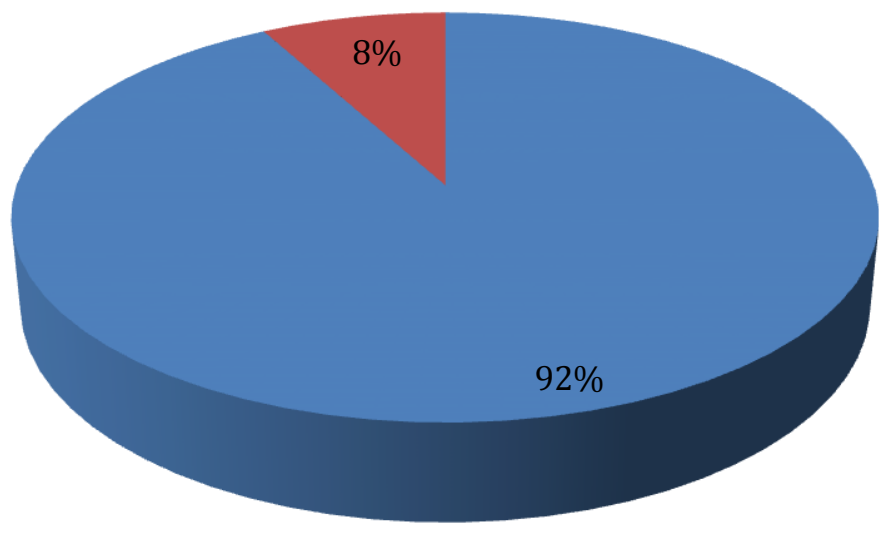

- Não contemplam disciplinas específicas

- Contempom disciplinas específicas

Autoria própria, 2019. 
Durante a avaliação dos Projetos Políticos dos Cursos, identificou-se que apenas uma IES (8\%), oferta, em seu PPC, disciplina relacionada a NC, sendo esta intitulada de: Doenças Infectocontagiosas. Mesmo assim, a disciplina é ofertada na matriz curricular na modalidade optativa.

Entretanto, não há garantia de que disciplina optativa seja cursada e, dessa forma, instrua os acadêmicos com relação a NC, pois, para Carvalho et. al. (2013), o processo de escolha para cursar disciplina optativa depende do interesse dos acadêmicos, e para reforçar a questão, observa-se que não foram apresentados, por esta instituição, registros acerca da oferta efetiva da disciplina.

Nos demais cursos, 92\%, não foram localizados nos PPCs, disciplinas e nem ementas que direcionem o conhecimento dos acadêmicos de fisioterapia sobre a temática.

Quando calculada a média de carga horária entre a disciplina optativa considerando a carga horária mínima de quatro mil horas, preconizada para o curso de Fisioterapia pelo Ministério da Educação (2009), a optativa que tem relação com NC, corresponde a 0,75\% da CH total do curso.

Em conformidade aos critérios estabelecidos nos materiais e métodos, o processo de construção da revisão integrativa obteve os seguintes resultados. Encontrou-se um total de 1.447 artigos, deste total, 336 no Periódico CAPES, 1.107 no LILACS e 4 no SciELO.

Dos 1.447 artigos encontrados, após os critérios de exclusão e inclusão, permaneceram 512. Foram excluídos 271 pela leitura do título e 173 pelo resumo. Após leitura na íntegra excluiu-se 50 devido inadequação à questão norteadora. O fluxograma a seguir (Figura 1) apresenta uma síntese do processo de obtenção dos artigos selecionados para a revisão integrativa.

Figura 1: Fluxograma de estratégia de buscas dos artigos.

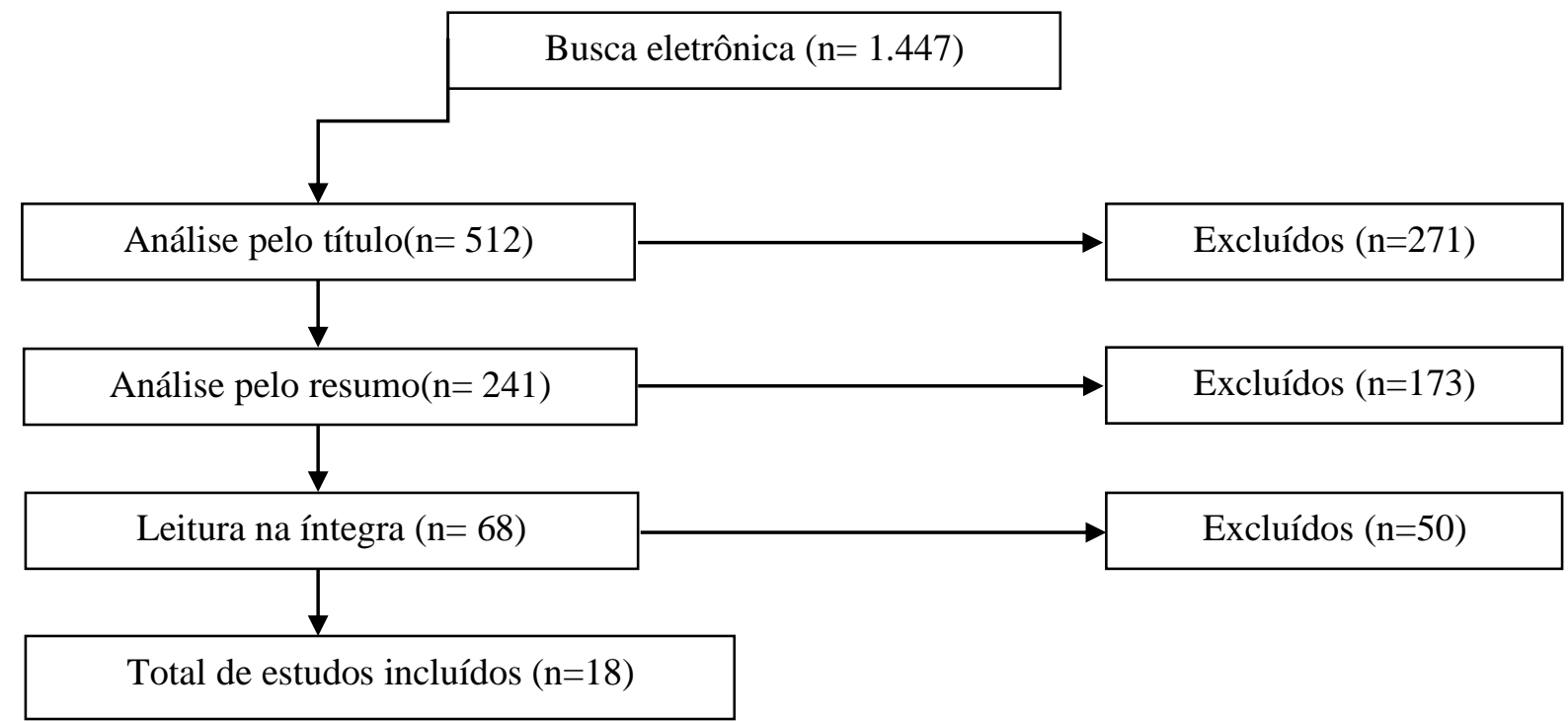

Autoria própria, 2019. 
Resultante ao processo descrito para seleção dos artigos, os mesmos foram organizados por meio de um quadro sinóptico (Quadro 1) contendo os seguintes dados: autor, ano, palavras-chave e sinopse.

Quadro1 - Sinopse dos estudos incluídos na revisão.

\begin{tabular}{|c|c|c|c|}
\hline Autor & Ano & Palavras-chave & Sinopse \\
\hline $\begin{array}{l}\text { Biscarde; Pereira- } \\
\text { Santos; Silva }\end{array}$ & 2014 & $\begin{array}{l}\text { Formação em saúde; Extensão } \\
\text { Universitária; Educação em Saúde; } \\
\text { Sistema Único de Saúde. }\end{array}$ & $\begin{array}{l}\text { Apresenta resultados de extensão universitária } \\
\text { promovendo ampliação da relação entre universidade- } \\
\text { sociedade. }\end{array}$ \\
\hline Bispo Junior & 2009 & $\begin{array}{l}\text { Fisioterapia; Educação Superior; } \\
\text { Formação Profissional; Ensino da } \\
\text { Saúde; Sistema Único de Saúde. }\end{array}$ & $\begin{array}{l}\text { Aborda algumas reflexões sobre a formação em } \\
\text { fisioterapia no Brasil, destacando o processo de } \\
\text { ampliação do número de cursos e vagas e a adequação } \\
\text { do modelo de formação às necessidades de saúde da } \\
\text { população. }\end{array}$ \\
\hline Campos et al. & 2001 & $\begin{array}{l}\text { Educação Médica; } \\
\text { Sistemas de Saúde; } \\
\text { docente-assistencial. }\end{array}$ & $\begin{array}{l}\text { Propôs um sistema de incentivos às instituições de } \\
\text { ensino superior, visando maior sintonia com o } \\
\text { paradigma da integralidade. }\end{array}$ \\
\hline Carvalho et al. & 2013 & $\begin{array}{l}\text { Curriculum vitae; Educação } \\
\text { Residência } \quad \text { Médica; } \\
\text { Extracurriculares. }\end{array}$ & $\begin{array}{l}\text { Investigou as escolhas de atividades formadoras feitas } \\
\text { por estudantes, com o fim de apreender a lógica dessas } \\
\text { escolhas no contexto institucional em que se } \\
\text { apresentam e no contexto social mais amplo das } \\
\text { sociedades. }\end{array}$ \\
\hline $\begin{array}{l}\text { Ceccim; } \\
\text { Feuerwerker }\end{array}$ & 2004 & $\begin{array}{l}\text { Educação permanente em saúde; } \\
\text { Educação dos profissionais de saúde; } \\
\text { Formação e práticas de saúde; } \\
\text { Formulação de políticas de formação } \\
\text { em saúde; Ensino em saúde. }\end{array}$ & $\begin{array}{l}\text { Apresenta o conceito de quadrilátero da formação para } \\
\text { a área da saúde: ensino, gestão, atenção e controle } \\
\text { social. }\end{array}$ \\
\hline $\begin{array}{ll}\text { Dias; } & \text { Cyrino; } \\
\text { Lastória } & \end{array}$ & 2007 & $\begin{array}{l}\text { Ensino superior; } \\
\text { preconceito; Fisioterapia }\end{array}$ & $\begin{array}{l}\text { Descreve e analisou o conhecimento de estudantes de } \\
\text { fisioterapia sobre hanseníase, antes do contato formal } \\
\text { na Universidade/Faculdade. }\end{array}$ \\
\hline $\begin{array}{l}\text { Escosteguy; } \\
\text { Pereira; Medronho }\end{array}$ & 2017 & $\begin{array}{l}\text { Vigilância Epidemiológica; Vigilância } \\
\text { em Saúde Pública; Serviços de } \\
\text { Vigilância } \quad \text { Epidemiológica; } \\
\text { Epidemiologia; Avaliação em saúde. }\end{array}$ & $\begin{array}{l}\text { Propõe uma reflexão sobre os usos e as perspectivas da } \\
\text { vigilância em saúde }\end{array}$ \\
\hline
\end{tabular}

Revista SUSTINERE, Rio de Janeiro, v. 7, n.1, p. 168-184, jan-jun, 2019 


\begin{tabular}{|c|c|c|c|}
\hline Gomes & 2013 & $\begin{array}{l}\text { Educação a Distância; Ensino } \\
\text { Superior; Universidade Aberta do } \\
\text { Brasil; Tecnologias educacionais. }\end{array}$ & $\begin{array}{l}\text { Discute aspectos relativos à presença das tecnologias } \\
\text { no Ensino Superior, começando pela Educação a } \\
\text { Distância. }\end{array}$ \\
\hline Jurdi et al. & 2018 & $\begin{array}{l}\text { Ensino superior; Terapia ocupacional; } \\
\text { Currículo. }\end{array}$ & $\begin{array}{l}\text { Relata o processo de revisão da matriz curricular, } \\
\text { através de quatro etapas, destacando-se os seguintes } \\
\text { aspectos: diminuição da carga horária total; mudanças } \\
\text { nas atividades práticas; flexibilização curricular com } \\
\text { introdução de módulos eletivos; maior articulação } \\
\text { entre eixos e módulos; e fortalecimento da área de } \\
\text { fundamentos e pesquisa. }\end{array}$ \\
\hline Meyer; Costa; Gico & 2006 & $\begin{array}{lr}\text { Ciências sociais; } & \text { Fisioterapia; } \\
\text { Transdisciplinaridade; } & \text { Processo } \\
\text { saúde-doença. } & \end{array}$ & $\begin{array}{l}\text { Aborda as interfaces sociais, buscando a compreensão } \\
\text { da saúde e da doença com base em uma concepção } \\
\text { transdisciplinar, por meio da religação dos saberes no } \\
\text { curso de Fisioterapia. }\end{array}$ \\
\hline Moura et al. & 2012 & $\begin{array}{l}\text { Serviços de saúde; Educação em } \\
\text { Odontologia; Gestantes; Saúde da } \\
\text { criança; Extensão comunitária. }\end{array}$ & $\begin{array}{l}\text { Descreve o impacto que as informações e ações } \\
\text { desenvolvidas em um programa de extensão } \\
\text { universitária exerceram na formação profissional de } \\
\text { egressos. }\end{array}$ \\
\hline Nunes & 2005 & $\begin{array}{l}\text { Saúde Coletiva, história; Saúde } \\
\text { Coletiva, prática pedagógica; Saúde } \\
\text { Coletiva, estrutura curricular. }\end{array}$ & $\begin{array}{l}\text { Aborda a constituição do campo da Saúde Coletiva no } \\
\text { Brasil em três aspectos: origens da Saúde Coletiva, } \\
\text { aspectos históricos da saúde no Brasil, a Saúde Coletiva } \\
\text { como prática pedagógica e perspectivas do campo. }\end{array}$ \\
\hline Silva & 2015 & $\begin{array}{lr}\text { Leptospirose; } & \text { Doenças } \\
\text { infectocontagiosas; } & \text { Notificação } \\
\text { compulsória de doenças. } & \end{array}$ & $\begin{array}{l}\text { Descreve dados retrospectivos sobre os números de } \\
\text { casos confirmados e de óbitos relacionados à } \\
\text { Leptospirose, no nordeste brasileiro entre os anos } 200 \text { a } \\
\text { 2013, e a relação de doenças de notificação compulsória } \\
\text { com o ensino em saúde. }\end{array}$ \\
\hline Silva; Oliveira & 2014 & $\begin{array}{l}\text { Notificações de doenças. Doenças } \\
\text { transmissíveis. Notificação. }\end{array}$ & $\begin{array}{l}\text { Contextualiza o funcionamento } \text { do serviço de } \\
\text { notificação compulsória vigente no Brasil e a } \\
\text { importância da atuação dos profissionais de saúde nos } \\
\text { processos de notificação. }\end{array}$ \\
\hline Soares et al. & 2002 & $\begin{array}{l}\text { Hepatite B; Exposição a agentes } \\
\text { biológicos; Odontologia; Estudantes; } \\
\text { Epidemiologia. }\end{array}$ & $\begin{array}{l}\text { Verificou o conhecimento e práticas de alunos sobre a } \\
\text { Hepatite B. }\end{array}$ \\
\hline
\end{tabular}




\begin{tabular}{|l|l|l|l|}
\hline Sousa et al. & 2012 & $\begin{array}{l}\text { Notificação de Doenças; Notificação } \\
\text { Compulsória; } \begin{array}{l}\text { Vigilância } \\
\text { Epidemiológica; Atenção Primária à } \\
\text { Saúde. }\end{array}\end{array}$ & $\begin{array}{l}\text { Avalia e comparou o conhecimento de profissionais da } \\
\text { saúde da Estratégia Saúde da Família sobre doenças e } \\
\text { agravos de notificação compulsória. }\end{array}$ \\
\hline Teixeira et al. & 1998 & $\begin{array}{l}\text { Vigilância Epidemiológica; Doenças } \\
\text { de Notificação Compulsória. }\end{array}$ & $\begin{array}{l}\text { Refere-se ao Sistema Nacional de Vigilância } \\
\text { Epidemiológica, principalmente, quanto ao processo de } \\
\text { revisão e seleção de doenças de Notificação } \\
\text { Compulsória. }\end{array}$ \\
\hline Vasconcelos & 1998 & $\begin{array}{l}\text { Educação em Saúde; Cuidados } \\
\text { Primários à Saúde; Doenças } \\
\text { Transmissíveis; Saúde Pública }\end{array}$ & $\begin{array}{l}\text { Aborda estratégias de combate às doenças infecciosas e } \\
\text { parasitárias nos serviços de atenção primária à saúde. }\end{array}$ \\
\hline
\end{tabular}

Autoria própria, 2019. 


\section{DISCUSSÃO}

As instituições formadoras dos profissionais de saúde têm perpetuado modelos tradicionalistas, centrados em aparelhos e tecnologias altamente especializadas, dependente de procedimentos e equipamentos de diagnóstico ou apoio terapêutico, deixando muitas vezes a formação profissional em saúde abstraída de debates críticos sobre os sistemas de estruturação do cuidado a saúde da população (CECCIM; FEUERWERKER, 2004).

Escosteguy, Pereira e Medronho (2017) chamam atenção para que haja uma melhor formação dos profissionais de saúde, seja na graduação ou durante a vida profissional, destacam ainda que, estes profissionais em suas diferentes especialidades, quando bem treinados/capacitados sobre o Sistema de Notificação vigente, são capazes de contribuir efetivamente com o monitoramento da saúde da população.

O controle das situações envolvendo NC demanda conhecimento e ações imediatas de vigilância por profissionais de saúde, ações estas, que envolve a comunicação imediata às autoridades sanitárias logo após a suspeita ou detecção de um único caso, para impedir o aparecimento e a disseminação de casos secundários (SOUSA, 2010; BRASIL, 2001).

Silva e Oliveira (2014) afim quem, a notificação de doenças infectocontagiosas oferece um meio valioso para vigiar a saúde da população, todavia, ainda há falta de conhecimento dos próprios profissionais e também dos discentes dos cursos de graduação da saúde, não só sobre as características clínicas das doenças, mas também sobre o sistema de notificação brasileiro.

Estudantes e equipes de saúde, quando devidamente qualificados, contribuem efetivamente com a NC, pois, o conhecimento sobre estas doenças e como notificá-las às autoridades sanitárias responsáveis, é fundamental para prevenção e controle de epidemias. Assim, uma melhor formação destes profissionais, seja na graduação ou durante a prática profissional otimizaria o programa de vigilância brasileiro (SILVA; OLIVEIRA, 2014).

Soares et al., (2002) avaliou o conhecimento e as práticas de estudantes da saúde sobre aspectos gerais das infecções e realizaçãodo atendimento a pacientes com doenças infectocontagiosas, foi observada uma deficiência no conhecimento quanto a estratégias para controle de enfermidades de NC. 
Foi destacado por Vasconcelos (1998) e Andrade (2012) que, profissionais de saúde graduados em Instituições de Ensino Superior que não contemplam em Projetos Políticos de Cursos, conteúdos específicos e que promovam o estudo doenças infectocontagiosas, podem apresentar dificuldade em reconhecer e atuar em tempo hábil no manejo adequado da saúde da população quanto ao Sistema de Notificação.

É imprescindível que os PPCs levem em consideração a carga horária de disciplinas, objetivando capacitar profissionais e conectá-los a às necessidades da sociedade brasileira facilitando o processo a construção e efetivação de políticas públicas, relevante para a sociedade e suas demandas, entretanto, nem sempre as $\mathrm{CH}$, conseguem solucionar todas as demandas de conteúdos a serem ofertados, mas, o avanço do conhecimento coloca para a IES o desafio de incorporar em seu ensino, outras estratégias, como a extensão, para o aprofundamento da reflexão sobre cuidado, saúde e ação social (JURDI, 2017).No âmbito da Fisioterapia, a estrutura e a organização dos PPCs ainda tem a herança biomédica da formação. Muitas vezes não direciona o curso para aspectos voltados ao sistema de saúde vigente, o SUS, com formação das demandas sociais e das políticas públicas de saúde (MEYER; COSTA; GICO, 2006).

Mesmo assim, este curso, Fisioterapia, tem se destacado como uma das graduações em maior crescimento numérico da área de saúde, por influências de contextos políticos, econômicos e sociais. Por outro lado, ainda é observado planejamento inadequado e estagnação de algumas instituições de ensino públicas e privadas sobre algumas temáticas, desencadeando assim uma deficiência no conhecimento destes profissionais (BISPO JUNIOR, 2009).

É importante que as IES permitam o rompimento do modelo de formação do fisioterapeuta curativo-reabilitador e privatista. Os cursos de Fisioterapia, conforme estabelecido nas diretrizes curriculares nacionais, devem adequar em sua formação ao interesse para perfil epidemiológico da população. A formação deste profissional, deve aproximar-se também da prevenção e da promoção à saúde (BISPO JUNIOR, 2009).

Sendo assim, a Fisioterapia enquanto profissão da área da saúde também tem o dever exercer a notificação e estar vigilantes aos acontecimentos nos estabelecimentos de saúde, pois, durante sua formação a IES deve propiciar ao acadêmico uma formação generalista, humanista, crítica e reflexiva, habilitando-o a atuar em todos os níveis de atenção à saúde (BRASIL, 2001; TEIXEIRA, 1998). 
Após formado, o fisioterapeuta egresso, deve apresentar-se capaz de contribuir com as diretrizes brasileira para controle e prevenção das doenças e agravos de NC, visto que, o bom funcionamento do sistema de vigilância brasileiro, depende também do conhecimento prévio sobre NC, adquirido durante ainda na graduação por este profissional (SILVA, 2015; BRASIL, 2007),

\section{CONCLUSÃO}

Considerando que a literatura científica aborda a formação adequada do Fisioterapeuta como estratégia para consolidação das atividades ministeriais em relação a Notificação Compulsória, faz-se necessário que ainda na graduação, este profissional possa aprender o manejo adequado do sistema brasileiro, não percorrendo apenas um caminho curativo-reabilitador, mas, que este, seja capaz de contribuir efetivamente com a promoção e proteção a saúde da população. Considerando ainda que nos Projetos Políticos dos Cursos que houve identificação mínima de número de disciplinas, carga horária e/ou conteúdos relacionados a NC, capazes de preparar o Fisioterapeuta, sugere-se, que sejam realizadas adequações nos PPCs e/ou em seu ementário, para que este conhecimento venha a ser ofertado, mesmo que nos moldes dos avanços tecnológicos da educação a distância ou projetos de extensão, pois, é inadmissível que o aluno de fisioterapia conclua sua graduação sem adquirir conhecimento relacionado a Notificação Compulsória.

\section{REFERÊNCIAS}

ANDRADE Lidiane Lima de. Construção de instrumentos para a documentação do processo de enfermagem em uma clínica de doenças infectocontagiosas [dissertação] [Internet]. João Pessoa: Universidade Federal da Paraíba; 2012. Disponível em <https://repositorio.ufpb.br/jspui/handle/tede/5086>. Acesso em 08 maio 2019.

BISCARDE Daniela Gomes dos Santos; PEREIRA-SANTOS, Marcos; SILVA, Lília Bittencourt. Formação em saúde, extensão universitária e Sistema Único de Saúde (SUS): conexões necessárias entre conhecimento e intervenção centradas na realidade e repercussões no processo formativo. Interface (Botucatu), Botucatu , V. 18, n. 48, p. 177-186, $2014 . \quad$ Disponível el <http://www.scielo.br/scielo.php?script=sci_arttext\&pid=S1414-32832014000100177\&lng=en\&nrm=iso>. Acesso em 08 maio 2019. 
BISPO JUNIOR José Patrício. Formação em fisioterapia no Brasil: reflexões sobre a expansão do ensino e os modelos de formação. Hist. cienc. saude-Manguinhos, Rio de Janeiro, v. 16, n. 3, p. 655668, Set. 2009. Disponível em <http://www.scielo.br/scielo.php?script=sci_arttext\&pid=S010459702009000300005\&lng=en\&nrm=iso>. Acesso em 15 maio 2018.

BRASIL. Conselho Nacional de Educação. Diretrizes curriculares nacionais do curso de graduação em fisioterapia. Diário Oficial da União, Brasília, DF, 4 mar. 2002. Disponível em: $<$ http://portal.mec.gov.br/cne/arquivos/pdf/CES042002.pdf>.Acesso em 2 maio 2018.

. Ministério da Saúde. Gabinete do Ministro. Portaria nº 204, de 17 de fevereiro de 2016. Define a Lista Nacional de Notificação Compulsória de doenças, agravos e eventos de saúde pública nos serviços de saúde públicos e privados em todo o território nacional, nos termos do anexo, e dá outras providências. Diário Oficial da União, Brasília, DF, 18 fev. 2016. Disponível em: <http://bvsms.saude.gov.br/bvs/saudelegis/gm/2016/prt0204_17_02_2016.html>. Acesso em 2 maio 2018.

. Ministério da Saúde. Secretaria de Vigilância em Saúde. Departamento de Vigilância Epidemiológica. Sistema de Informação de Agravos de Notificação - Sinan: normas e rotinas.[Internet]. 2.ed. Brasília: Ministério da Saúde; 2007 Disponível em: <http://bvsms.saude.gov.br/bvs/publicacoes/07_0098_M.pdf> Acesso em 12 Maio de 2018.

- Ministério da Saúde. Câmara de Educação Superior. Decreto n. 2, de 18 de Junho de 2007. Dispõe sobre carga horária mínima e procedimentos relativos à integralização e duração dos cursos de graduação, bacharelados, na modalidade presencial. Disponível em: <http://portal.mec.gov.br/cne/arquivos/pdf/2007/rces002_07.pdf>Acesso em 6 maio 2018.

. Parecer CNE/CES 1.210/2001 de 7 de dezembro de 2001. Institui Diretrizes Curriculares Nacionais dos Cursos de Graduação em Fisioterapia, Fonoaudiologia e Terapia Ocupacional [Internet]. Ministério da Educação. Diário Oficial da União. Brasília. 2001. Disponível em:<http://portal.mec.gov.br/cne/arquivos/pdf/pces1210_01.pdf>Acesso em 12 maio 2018

CAMPOS Francisco Eduardo de, FERREIRA José Roberto, FEUERWEKER Laura, SENA Roseni Rosangela de, CAMPOS João José Batista, CORDONI-JR Luis, CORDEIRO Hésio. Caminhos para aproximar a formação de profissionais de saúde das necessidades da Atenção Básica. Ver BrasEduc Méd. Rio de Janeiro, v. 25, n. 2, p. 539, jun. 2001. Disponível em $<$ <ttps://www.pucsp.br/prosaude/downloads/bibliografia/caminhos_aproximar.pdf>. Acesso em 8 maio 2018.

CARVALHO, Maria Bernadete de, RIBEIRO, Maria Mônica Freitas, SILVA, Luciana Diniz, SHIMOMURA, Flávio Martins. A composição do curriculum vitae entre estudantes de medicina e seus condicionantes. Rev. bras. educ. med., Rio de Janeiro, v. 37, n. 4, p. 483-491, Dec. 2013. <http://www.scielo.br/scielo.php?pid=S0100-

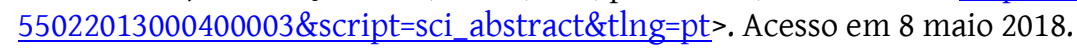

CECCIM Ricardo Burg, FEUERWERKER Laura C. M. O quadrilátero da formação para a área da saúde: ensino, gestão, atenção e controle social. Physis, Rio de Janeiro, v. 14, n. 1, p. 41-65, jun. 2004. Disponível em <http://www.scielo.br/scielo.php?script=sci_arttext\&pid=S0103-73312004000100004\&lng=pt\&nrm=iso>.

Acesso em 15 maio 2018

DIAS Andréia, CYRINO Eliana Goldfarb, LASTÓRIA Joel Carlos. Conhecimentos e necessidades de aprendizagem de estudantes de fisioterapia sobre a hanseníase. Hansen. int. Bauru, p. 9-18, 2007. <http://www.ilsl.br/revista/detalhe_artigo.php?id=10905>. Acesso em 19 maio 2018.

ESCOSTEGUY Claudia Caminha, PEREIRA Alessandra Gonçalves Lisbôa, MEDRONHO Roberto de Andrade. Três décadas de epidemiologia hospitalar e o desafio da integração da Vigilância em Saúde: reflexões a partir de um caso. Ciênc. saúde coletiva, Rio de Janeiro, v. 22, n. 10, p. 3365-3379, Oct. 2017. Disponível em<http://www.scielo.br/scielo.php?script=sci_arttext\&pid=S1413-81232017021003365\&lng=en\&nrm=iso>. Acesso em 07 meio 2019.

GOMES Luiz Fernando. EAD no Brasil: perspectivas e desafios. Avaliação (Campinas), Sorocaba, v. 18, n. 1, p. 13-22, Mar. 2013. [acesso em 12 de a Maio de 2018]. Disponível em: 
<http://www.scielo.br/scielo.php?script=sci_arttext\&pid=S1414-40772013000100002\&lng=en\&nrm=iso>. Acesso em 13 maio 2018

JURD Andrea Perosa Saigh, NICOLAU Stella Maris, FIGUEIREDO Lúcia da Rocha Uchôa, ROSSIT Rosana Aparecida Salvador, MAXIMINO Viviane Santalucia, BORBA Patrícia Leme de Oliveira. Revisitar processos: revisão da matriz curricular do curso de Terapia Ocupacional da Universidade Federal de São Paulo. Interface (Botucatu), Botucatu, v. 22, n. 65, p. 527-538, Abr. 2018. Disponível em: <http://www.scielo.br/scielo.php?script=sci_arttext\&pid=S141432832018000200527\&lng=en\&nrm=iso>. Acesso em 13 de Nov. 2018.

MEYER Patrícia Froes, COSTA Íris Céu Clara, GICO, Vânia Vasconcelos. Ciências sociais e fisioterapia: uma aproximação possível. História, Ciências, Saúde-Manguinhos, Rio de Janeiro, v.13, n.4, p.877-890. 2006. Disponível em<http://www.scielo.br/scielo.php?pid=S010459702006000400006\&script=sci_abstract\&tlng=pt>. Acesso em 14 maio 2018

MINISTÉRIO DA EDUCAÇÃO. Conselho Nacional de Educação Câmara de Educação Superior. Resolução CNE/CES 4, de 6 de abril de 2009. Carga horária mínima e procedimentos relativos à integralização e duração dos cursos de graduação em Biomedicina, Ciências Biológicas, Educação Física, Enfermagem, Farmácia, Fisioterapia, Fonoaudiologia, Nutrição e Terapia Ocupacional, bacharelados, na modalidade presencial. Diário $\begin{array}{llllll}\text { Oficial União. 07abr } & \text { 2009.Seção1. } & \text { p. } & 27 . & \text { Disponível } & \text { em: }\end{array}$ <http://portal.mec.gov.br/dmdocuments/rces004_09.pdf>Acesso em 11 nov 2018

MOURA Lúcia de Fátima Almeida de Deus, PIAULINO Raíra Jessica Barbosa, ARAÚJO Ítalo Frota, MOURA Marcoeli Silva de, LIMA Cacilda Castelo Branco, EVANGELISTA Lidiane de Morais. Impacto de um projeto de extensão universitária na formação profissional de egressos de uma universidade pública. Rev. odontol. UNESP, Araraquara, v. 41, n.5, p. 348-352, Out. 2012. Disponível em $<$ http://www.scielo.br/scielo.php?script=sci_arttext\&pid=\$1807-25772012000500009\&lng=en\&nrm=iso>. Acesso em 08 maio 2019.

Nunes Everardo Duarte. Pós-graduação em saúde coletiva no Brasil: histórico e perspectivas. Physis.v. 15, n. 1, p. 13-38. Jun. 2005. <http://www.ilsl.br/revista/detalhe_artigo.php?id=10905>. Acesso em 08 maio 2019.

SILVA, Geraedson Aristides da. Enfoque sobre a leptospirose na região nordeste do Brasil entre os anos de 2000 a 2013. Acta BiomedicaBrasiliensia. v. 6, n. 1, p. 101-108, jul. 2015. Disponível em: $<$ http://www.redalyc.org/articulo.oa?id=63770303>Acesso em 13 maio 2018

SILVA Geraedson Aristides da, OLIVEIRA Cilmery Marly Gabriel de. O registro das doenças de notificação compulsória: a participação dos profissionais da saúde e da comunidade. RevEpidemiolControlInfect. v. 4, n.3, p. 215-220, jul/set 2014. Disponível em: <http://www.redalyc.org/articulo.oa?id=63770303>Acesso em 13 maio 2018

SOARES Maria Sueli Marques, ANGELO Angelinne Ribeiro, QUEIROGA Andréa Sarmento, GONÇANVES Luiz Felipe Fernandes, SANTOS Suennya Dantas dos, SOUSA Caroline D'Fátima Santos de. Conhecimento de estudantes de odontologia da UFPB com relação à Aids e hepatite B. João Pessoa.Pesq Bras Odontoped Clin Integr, João Pessoa, 7(3): 211-216, set./dez. 2007. Disponível em: <http://www.redalyc.org/articulo.oa?id=63770303>Acesso em 13 maio 2018

SPANA Thaís Moreira, RODRIGUES Roberta Cunha Matheus, LOURENÇO Laura Bacelar de Araújo, MENDEZ Roberto Della Rosa, GALLANI Maria Cecília Bueno Jayme. Integrative review: behavioral interventions for physical activity practice. Rev Latino-am Enfermagem, Ribeirão Preto, SP, v. 17, n. 6, p. 1057-1064, 2009.Disponível em: <http://www.scielo.br/scielo.php?script=sci_arttext\&pid=S0104$11692009000600020>$ Acesso em 13 maio 2018

SOUSA Selônia Patrícia Oliveira, MASCARENHAS Márcio Dênis Medeiros, SILVA Maria da Conceição Brandão, ALMEIDA Rúbria Araújo Marins de. Conhecimento sobre doenças e agravos de notificação compulsória entre profissionais da Estratégia Saúde da Família no município de Teresina, estado do Piauí, Brasil - 
2010. Epidemiol. Serv. Saúde, Brasília, v. 21, n. 3, p. 465-474, set. 2012. Disponível em <http://scielo.iec.gov.br/scielo.php?script=sci_arttext\&pid=S1679-49742012000300012\&lng=pt\&nrm=iso>. Acesso em 15 maio 2018

TEIXEIRA Maria da Glória, PENNA Gerson Oliveira, RISI João Batista, PENNA Maria Lucia, ALVIN Maria Fernanda, MORAES José Cássio de. Seleção das doenças de notificação compulsória: critérios e recomendações para as três esferas de governo. Inf. Epidemiol. Sus. n. 7, v.1, p. 7-28. 1998.Disponível em <http://scielo.iec.gov.br/scielo.php?script=sci_arttext\&pid=S1679-49742012000300012\&lng=pt\&nrm=iso >. Acesso em 20 maio 2018

Vasconcelos Eymard Mourão. Educação popular como instrumento de reorientação das estratégias de controle das doenças infecciosas e parasitárias. Cad. Saúde Pública.n. 14, supple, 2, p, 39-57. 1998. <http://www.scielo.br/pdf/csp/v14s2/1324>. Acesso em 16 maio 2018.

\section{(cc) $\mathrm{BY}$}

Este trabalho está licenciado com uma Licença Creative Commons - Atribuição 4.0 Internacional. 